\title{
INVENTÁRIO DA ARBORIZAÇÃO URBANA NAS PRAÇAS DE CARAGUATATUBA-SP
}

\author{
INVENTORY OF URBAN AFFORESTATION IN THE PUBLIC SQUARES OF \\ CARAGUATATUBA-SP
}

\author{
Danilo Cristiano Ramos Prado ${ }^{1}$, Karolina Marie Alix Benedictte Van Sebroeck Doria ${ }^{2}$
}

\section{RESUMO}

A arborização urbana é indispensável para a população de um município, pois traz benefícios como a diminuição da radiação solar, de enchentes, de dióxido de carbono e o aumento da umidade do ar. $O$ estudo realizou o inventário da arborização urbana nas praças de Caraguatatuba-SP. Os componentes arbóreos foram identificados taxonomicamente e classificados de acordo com o porte, disposição e densidade de distribuição. As espécies foram categorizadas em nativas ou exóticas e classificadas segundo a lista de espécies da flora do Brasil ameaçadas de extinção. Os equipamentos urbanos presentes foram inventariados. Identificou-se 59 praças no município. Foram inventariados 2.233 indivíduos arbóreos, pertencentes a 161 espécies, 30 ordens e 69 famílias botânicas, apresentando diversidade $\mathrm{H}^{\prime}=4,16$. As ordens mais abundantes foram Arecales $(27 \%)$, seguida por Myrtales $(8,7 \%)$ e Aspagarales ( $8,4 \%)$. O porte arbóreo foi o mais abundante (37\%), seguido de arbustos (34\%) e herbáceas $(17 \%)$. A densidade arbórea da disposição vegetal nas praças foi de agrupados em (43\%) seguido por parcialmente isolado (42\%) e isolado (15\%). A disposição dos indivíduos foi casual (32\%), difusa (29\%) e pontual (23\%). Dentre as espécies apenas $30 \%$ são nativas. Foram identificadas quatro espécies com diferentes graus de ameaçadas na Lista Vermelha da União Internacional para Conservação da Natureza. Quanto ao mobiliário presente, verificou-se que a iluminação pública está presente em $28 \%$ das praças, bancos em $22 \%$ e lixeiras em $21 \%$. Apesar do alto índice de diversidade faz-se necessário o enriquecimento nos plantios das áreas urbanas, priorizando-se espécies nativas e consequentemente aumentando assim os serviços ecossistêmicos.

Palavras-chave: Áreas verdes; Ecologia urbana; Gestão urbana; Planejamento urbano.

\begin{abstract}
Urban afforestation is indispensable for the population of a municipality, as it brings benefits such as the reduction of solar radiation, floods, carbon dioxide and the increase in air humidity. The study carried out an inventory of urban afforestation in the squares of Caraguatatuba-SP. The arboreal components were taxonomically identified and classified according to size, disposition and distribution density. The species were categorized as native or exotic and classified according to the list of species of Brazilian flora threatened with extinction. The urban equipment present was inventoried. A total of 59 squares were identified in the municipality, being 2,233 arboreal individuals were inventoried, belonging to 161 species, 30 orders and 69 botanical families, presenting diversity $\mathrm{H}^{\prime}=4.16$. The most abundant orders were Arecales (27\%), followed by Myrtales (8.7\%) and Aspagarales (8.4\%). The tree size was the most abundant (37\%), followed by shrubs $(34 \%)$ and herbaceous $(17 \%)$. The tree density of the plant layout in the squares was grouped into $(43 \%)$ followed by partially isolated $(42 \%)$ and isolated $(15 \%)$. The disposition of individuals was casual $(32 \%)$, diffuse $(29 \%)$ and punctual $(23 \%)$. Among the species, only $30 \%$ are native. Four species with different degrees of threat have been identified on the International Union for Conservation of Nature's Red List. As for the furniture present, it was found that public lighting is present in $28 \%$ of the squares, banks in $22 \%$ and dumps in $21 \%$. Despite the high rate of diversity, it is necessary to enrich plantings in urban areas, giving priority to native species and, consequently, increasing ecosystem services.
\end{abstract}

Keywords: Green areas; Urban ecology; Urban planning; Urban management.

Recebido em 04.10.2020 e aceito em 19.04.2021

1 Biólogo. Graduado em Ciências Biológicas. Centro Universitário Módulo. Caraguatatuba/SP. Email: danilo_hyuuga@hotmail.com 2 Engenheira Florestal, Doutorado em Ciência Florestal. Professora no Centro Universitário Módulo - Universidade Cruzeiro do Sul. Caraguatatuba/SP. Email: karolina.doria@modulo.edu.br 


\section{INTRODUÇÃO}

Os espaços livres públicos são em sua maioria classificados como "espaços de uso comum do povo", o que determina sua qualificação como livre. Podem pertencer ao sistema viário do município como as ruas, avenidas, alamedas e bulevares, ou ao sistema de áreas verdes, como as praças e os parques. Em qualquer uma das funções, os espaços livres são bens imóveis pertencentes a diferentes esferas de governo, como federal, estadual ou municipal. Isto determina sua qualificação enquanto espaço público (PREFEITURA DO MUNÍCÍPIO DE SÃO PAULO, 2016).

As cidades representam a forma de ocupação do território que concentra a moradia da maior parte da população humana em praticamente todas as partes do mundo, responsáveis por reunir um conjunto significativo de serviços públicos e privados, de produção industrial e trocas comerciais, de intenso intercâmbio cultural, de aglomeração de pessoas e capital (FARIAS et al., 2017).

O crescimento urbano desordenado é, hoje, um problema global, por tanto, a avaliação de desempenho, por meio de ferramentas para a certificação de desenvolvimento urbano sustentável surge como uma alternativa para orientar desenvolvedores imobiliários urbanos na tomada de decisão. Neste contexto, torna-se importante reverter o quadro de impactos ambientais negativos em que a maioria das cidades se encontra especialmente aquelas dos países subdesenvolvidos. Para tanto, é necessário que o modo com que as cidades são organizadas e gerenciadas seja aprimorado, de forma que haja um uso mais eficiente dos recursos (FIGUEIREDO; ENSSLIN; MATOS, 2017).

As áreas verdes são fundamentais para a vida urbana, por isso, alguns cuidados são necessários para evitar desequilíbrios ecológicos relacionados, principalmente à perda da diversidade ocasionada por plantios homogêneos. A predominância de poucas espécies na arborização de uma cidade traz sérias consequências para o ecossistema urbano, como o aumento de gases poluentes na atmosfera, alterações no microclima, redução e evasão da fauna, assim como o ataque de pragas e doenças, haja vista que a diversidade da vegetação é de suma importância para a ampliação e fixação da fauna, e para a manutenção do equilíbrio biológico e o controle de pragas (DAMO; HEFLER; JACOBI, 2015).

As praças públicas são representações de áreas verdes, tendo como finalidade principal o lazer. Por estarem em uma área urbana são sistemas frágeis e complexos e exigem administração e planejamento cuidadoso, com os objetivos de otimizar as funções da arborização e reduzir custos. Conhecer a composição florística e a estrutura fitossociológica das Praças de uma cidade é importante para que se possa entender a dinâmica desta vegetação, 
bem como para dar suporte às ações de preservação e melhoria na diversidade dessas áreas (TEIXEIRA et al., 2016).

O manejo e o planejamento da arborização urbana começam por um inventário, os inventários são essenciais para localizar pontos para plantio, identificar necessidades de manejo e localizar riscos relacionados a árvores que estejam necessitando de reparos ou remoção (BENATTI et al. 2012). O inventário da arborização urbana pode ser conceituado como catalogação das espécies arbóreas plantadas em uma cidade. De forma análoga ao inventário florestal realizado em florestas plantadas ou nativas, o inventário das árvores plantadas nas cidades pode ser feito por meio de censo ou de amostragem. Podem ser considerados no inventário as árvores plantadas em determinados bairros, verificar as árvores distribuídas em praças e parques e classificando-os de acordo com sua disposição, localização, estado fitossanitário e entre outros atributos (SANTOS; JOSÉ; SOUSA, 2019).

Diante disso, o presente trabalho teve como objetivo realizar o inventário arbóreo de 59 Praças públicas do município de Caraguatatuba, SP, utilizando método quali-quantitativo, de forma a fornecer subsídios ao planejamento e manutenção da arborização urbana ao município.

\section{MATERIAL E MÉTODOS}

Caraguatatuba está localizada na Região Administrativa de São José dos Campos, no Litoral Norte de São Paulo com latitude aproximada de $23^{\circ} 37^{\prime} 21^{\prime \prime}$ S e longitude de $45^{\circ} 24^{\prime} 43^{\prime \prime}$ W. Possui aproximadamente $484,947 \mathrm{~km}^{2}$ de área territorial (INSTITUTO BRASILEIRO DE GEOGRAFIA E ESTATÍSTICA, 2019). Apresenta classificação climática de Köopen como clima Af - Clima tropical sem estação seca, com maior pluviosidade nos meses de verão (janeiro) com $251 \mathrm{~mm}$ e a média do período mais seco (junho) com 66,3 mm (CLIMATE DATE, 2021). A cidade apresenta representado na Figura 1.

O estudo foi realizado entre os meses de maio a outubro de 2019 nas praças catalogadas pela Secretaria de Urbanismo do município. Estas foram identificadas e delimitadas no programa Google Earth e os componentes arbóreos foram identificados in loco.

O material utilizado para a identificação das espécies foram livros específicos como os três volumes do "Manual de Identificação e Cultivo de Plantas Arbóreas Nativas do Brasil" Vol. 1, 2 e 3 (LORENZI, 1992; LORENZI, 1998; LORENZI, 2017). 


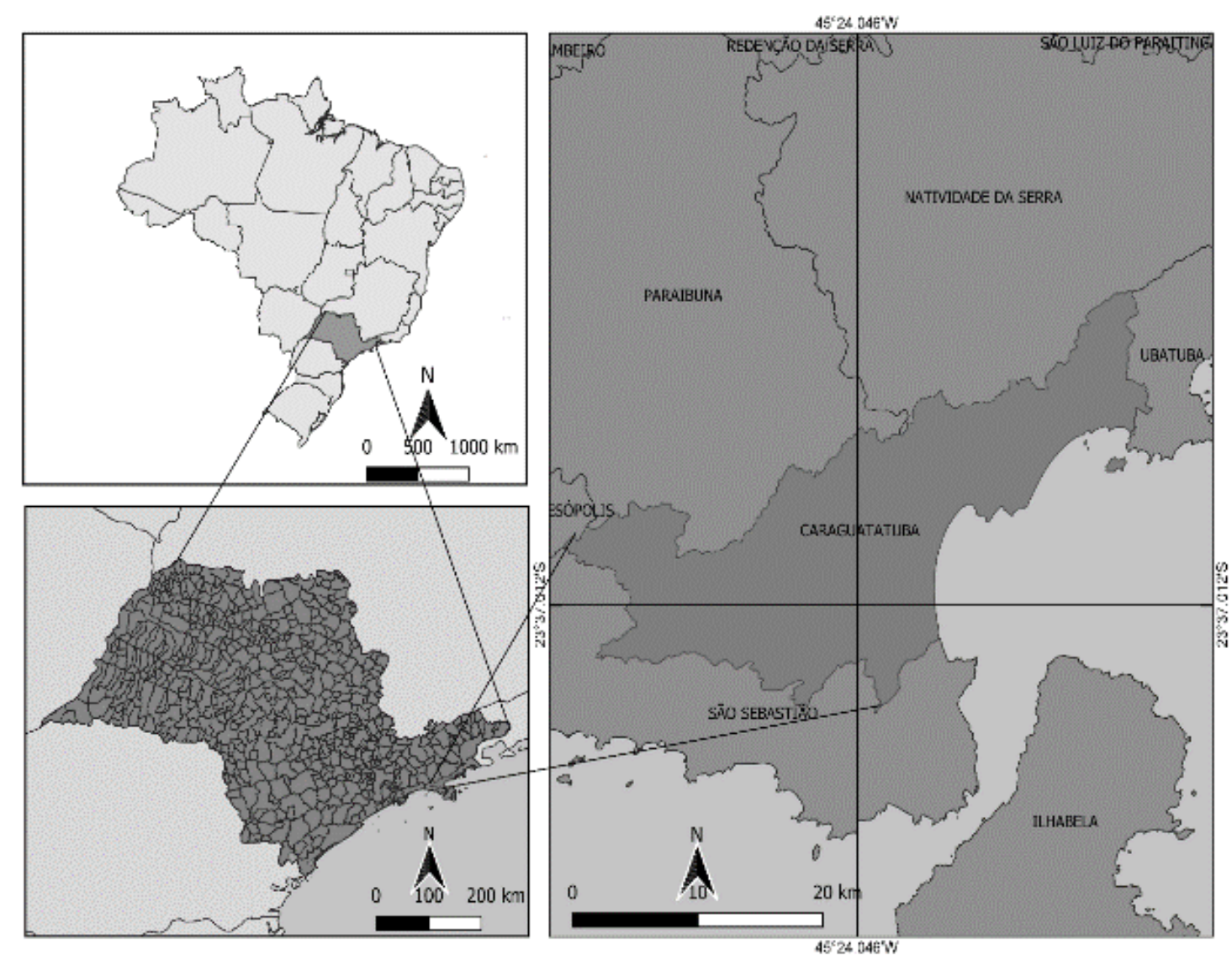

Fonte: Elaborado pelos autores no Quantum Gis, 2020.

Figura 1. Localização do município em relação ao Estado de São Paulo e no Brasil

Figure 1. Location of the municipality in relation to the State of São Paulo and in Brazil

As espécies foram classificadas de acordo com o nível de ameaça de extinção segundo a lista de espécies da flora do Brasil ameaçadas de extinção, publicada no Livro Vermelho da Flora do Brasil (MARTINELLI; MORAES, 2013) bem como na Portaria MMA 443, de 17 de dezembro de 2014 (MINISTÉRIO DO MEIO AMBIENTE, 2014).

Os componentes arbóreos foram identificados quanto ao seu epíteto específico em todas as praças. Houve contagem do número de indivíduos e espécie, assim como sua classificação perante origem e grupo.

A arborização destas praças identificadas foi classificada de acordo com os métodos de Peixoto, Labaki e Santos (1995) que classificam a estrutura arbórea de acordo com a disposição e densidade da estrutura vegetal (Figura 2). 


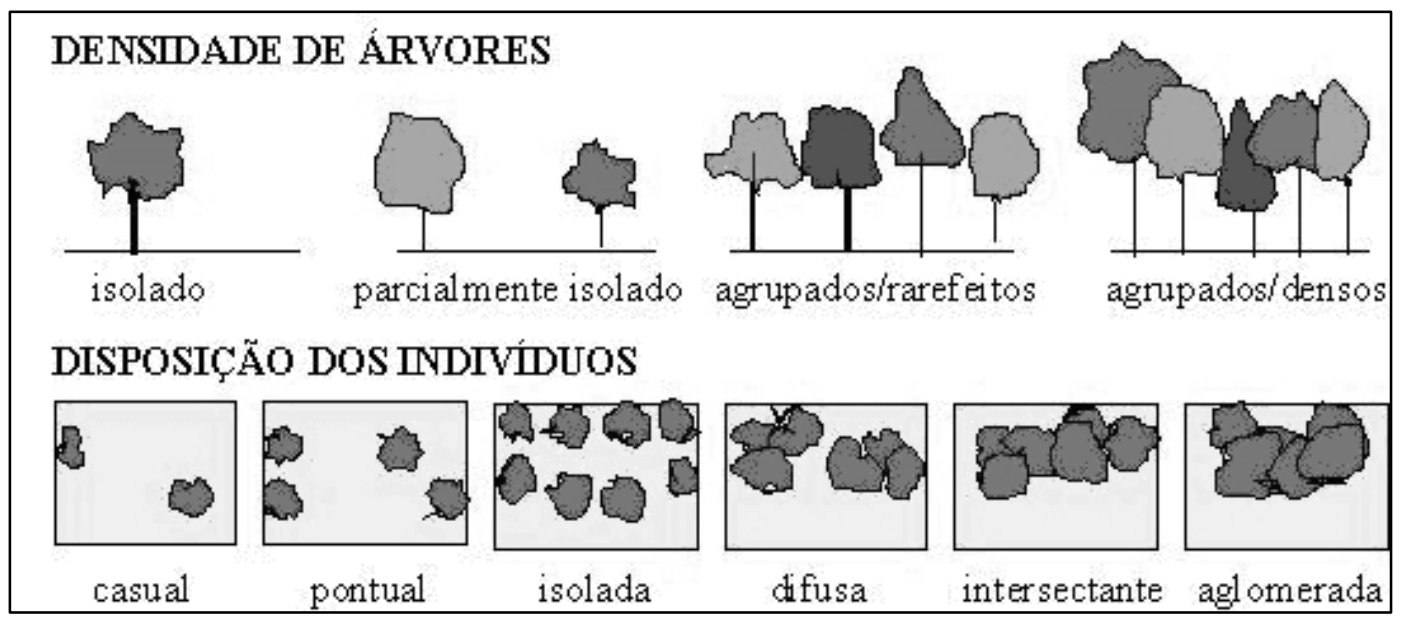

Fonte: Peixoto; Labaki; Santos, 1995.

Figura 2. Disposição e densidade da estrutura vegetal para classificação da estrutura arbórea Figure 2. Arrangement and density of plant structure for classification of the tree structure

O mobiliário urbano é um elemento importante em projetos de arborização urbana, pois eles agem como um meio de interação da população com o cenário proporcionado pelas árvores, sendo, portanto, realizado in loco. Todos os equipamentos presentes em cada praça foram anotados, a fim de verificar se há incentivo à utilização destes espaços.

As coletas em campo serviram como base para o cálculo do Índice de diversidade de Shannon-Wiener (Kramer e Kruper, 2012):

$$
H^{\prime}=-\sum_{i=1}^{s} P_{i} \ln P_{i}
$$

Em que:

H' = Índice de Shannon-Weaver

$\mathrm{p}_{\mathrm{i}}=$ abundância relativa (proporção) da espécie i na amostra

$\mathrm{n}_{\mathrm{i}}=$ número de indivíduos da espécie $\mathrm{i}$

$\mathrm{N}=$ Número de indivíduos total da amostra

\section{RESULTADOS E DISCUSSÃO}

Foram identificadas 59 praças públicas no município. Nestes locais foram catalogados 2233 indivíduos, pertencentes a 161 espécies, 30 ordens e 69 famílias botânicas. As ordens mais abundantes foram as ordens Arecales, seguido da ordem Myrtales, Aspagarales, Fabales e Rosales, conforme a Figura 3. 


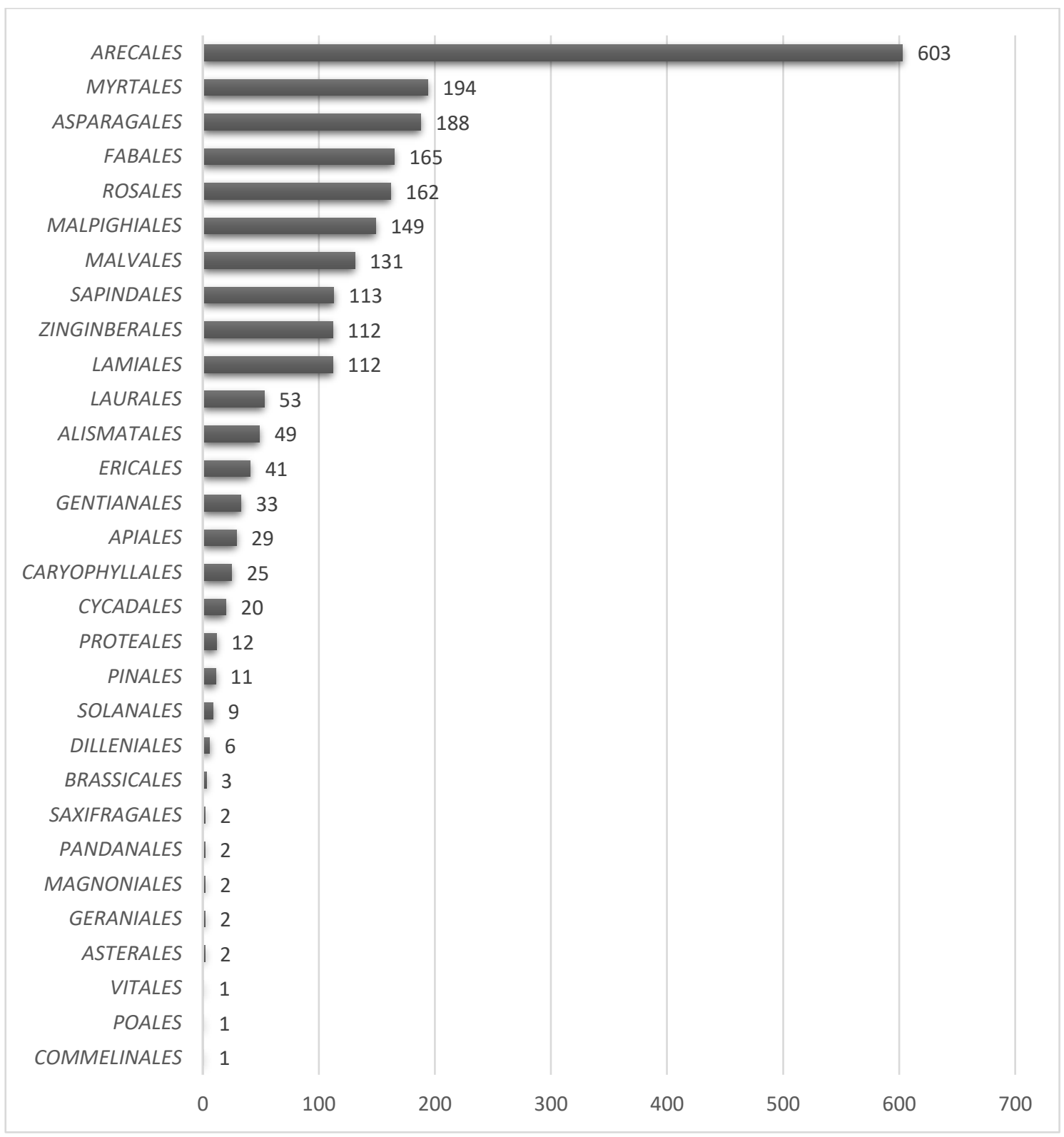

Fonte: Autores, 2020.

Figura 3. Frequência de indivíduos por ordem botânica nas praças de Caraguatatuba-SP Figure 3. Frequency of individuals by botanical order in the squares of Caraguatatuba-SP

As famílias mais abundantes em indivíduos foram as famílias Arecaceae, seguido por Fabaceae, Moraceae, Malvaceae e Clusiaceae, conforme a Figura 4. 


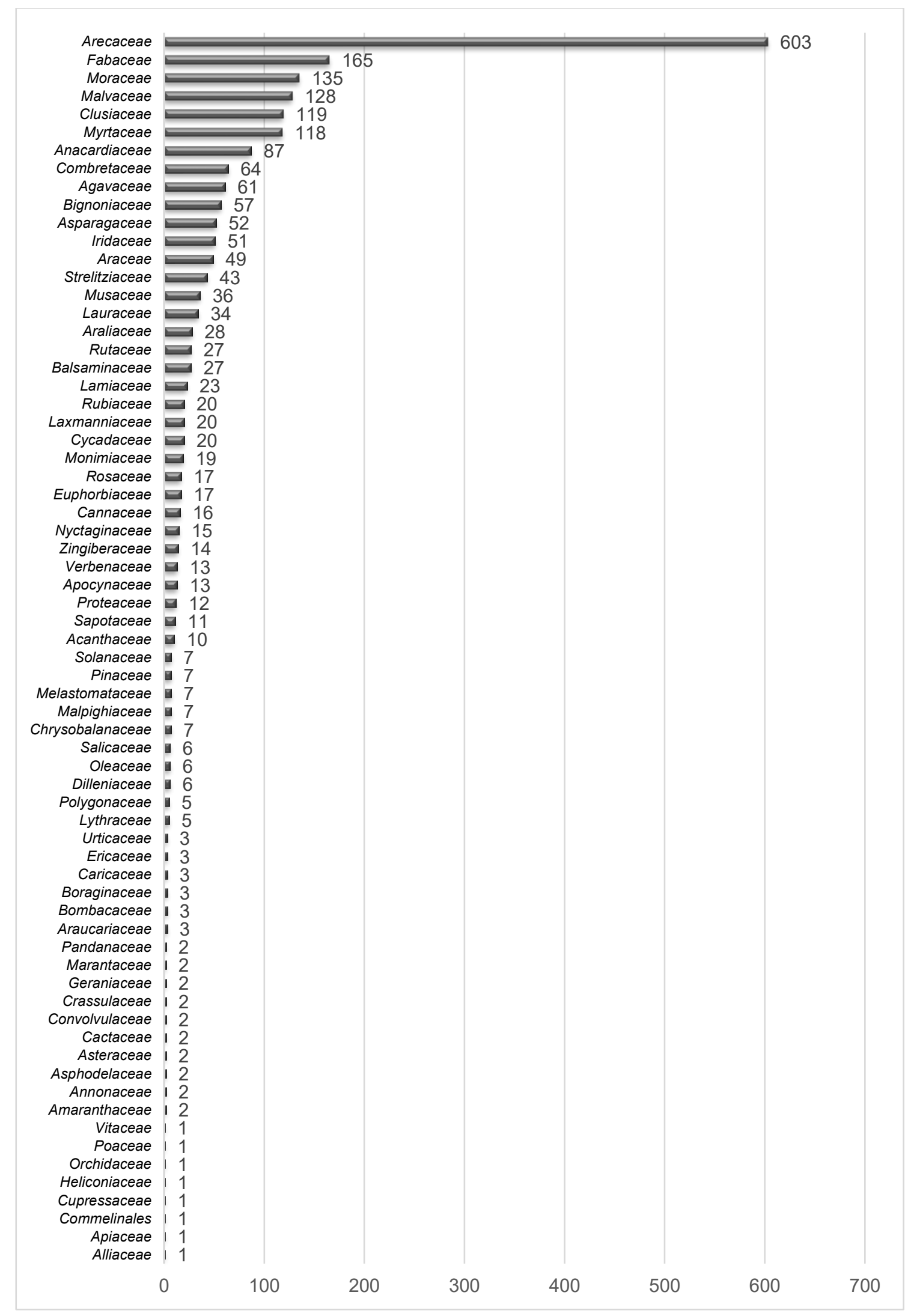

Fonte: autores, 2020.

Figura 4. Quantidade de indivíduos identificados nas praças por família botânica Figure 4. Number of individuals identified in the squares by botanical family 
Baseada na origem das espécies que ocorrem nas praças nota-se a predominância de exóticas em 70,85\% (ou 1582 indivíduos), enquanto outros 30\% (ou 651 indivíduos) são nativos. $\mathrm{Na}$ figura 5, podemos observar a Densidade Relativa (DR) das espécies nativas identificadas, e dentre elas podemos destacar as espécies Clusia fluminensis Planch. \& Triana (Abaneiro) DR= $5,33 \%$, seguido da espécie Palmeira Syagrus romanzoffiana (Cham) Glassman (Jerivá) DR= $4,16 \%$ e da espécie Cocos nucifera L. (Coco-da-Baía) DR= 3,94.

\begin{tabular}{|c|c|c|c|c|c|}
\hline Família & Nome científico & Nome popular & $\mathbf{N}^{\circ}$ & DR (\%) & 0 \\
\hline Clusiaceae & Clusia fluminensis Planch. \& Triana & Abaneiro & 119 & 5,33 & $\mathrm{~N}$ \\
\hline Arecaceae & Syagrus romanzoffiana (Cham) Glassman & Palmeira Jerivá & 93 & 4,16 & $\mathrm{~N}$ \\
\hline Arecaceae & Cocos nucifera L. & Coco-da-Baía & 88 & 3,94 & $\mathrm{~N}$ \\
\hline Myrtaceae & Psidium guajava L. & Goiaba & 55 & 2,46 & $\mathrm{~N}$ \\
\hline Bignoniaceae & Handroanthus sp. & Ipê & 47 & 2,1 & $\mathrm{~N}$ \\
\hline Myrtaceae & Eugenia uniflora L. & Pitanga & 39 & 1,75 & $\mathrm{~N}$ \\
\hline Anacardiaceae & Schinus terebinthifolius Raddi & Aroeira & 38 & 1,7 & $\mathrm{~N}$ \\
\hline Fabaceae & Clitoria fairchildiana R.A. Howard & Sombreiro & 36 & 1,61 & $\mathrm{~N}$ \\
\hline Fabaceae & Inga edulis Mart. & Ingá & 24 & 1,07 & $\mathrm{~N}$ \\
\hline Fabaceae & Bauhinia forficata Link & Pata de Vaca & 15 & 0,67 & $\mathrm{~N}$ \\
\hline Fabaceae & Mimosa tenuiflora (Willd.) Poir. & Jurema Preta & 14 & 0,63 & $\mathrm{~N}$ \\
\hline Zingiberaceae & Costus spicatus (Jacq.) Sw & Cana do Brejo & 14 & 0,63 & $\mathrm{~N}$ \\
\hline Myrtaceae & Psidium cattleianum Sab. & Araçá & 12 & 0,54 & $\mathrm{~N}$ \\
\hline Chrysobalanaceae & Licania tomentosa (Benth.) Fritsch & Oiti & 7 & 0,31 & $\mathrm{~N}$ \\
\hline Malvaceae & Hibiscus bifurcatus Cav. & Algodoeiro Bravo & 5 & 0,22 & $\mathrm{~N}$ \\
\hline Melastomataceae & Tibouchina heteromalla Cogn. & Orelha de Onça & 5 & 0,22 & $\mathrm{~N}$ \\
\hline Solanaceae & Solanum lycocarpum St. Hil. & Lobeira & 4 & 0,18 & $\mathrm{~N}$ \\
\hline Boraginaceae & Cordia verbenacea D.C & Erva Baleeira & 3 & 0,13 & $\mathrm{~N}$ \\
\hline Bombacaceae & Bombacopsis glabra (Pasq.) A. Robyns & $\begin{array}{l}\text { Castanha do } \\
\text { Maranhão }\end{array}$ & 3 & 0,13 & $\mathrm{~N}$ \\
\hline Urticaceae & Cecropia peltata L. & Embaúba & 3 & 0,13 & $\mathrm{~N}$ \\
\hline Arecaceae & Euterpe edulis Mart. & Palmito Juçara & 2 & 0,09 & $\mathrm{~N}$ \\
\hline Fabaceae & $\begin{array}{l}\text { Paubrasilia echinata (Lam.) Gagnon, } \\
\text { H.C.Lima \& G.P.Lewis }\end{array}$ & Pau Brasil & 2 & 0,09 & $\mathrm{~N}$ \\
\hline Fabaceae & $\begin{array}{l}\text { Piptadenia gonoacantha (Mart.) J. F. } \\
\text { Macbr. }\end{array}$ & Pau Jacaré & 2 & 0,09 & $\mathrm{~N}$ \\
\hline Fabaceae & Senna obtusifolia (L.) H.S.Irwin \& Barneby & Mata Pasto & 2 & 0,09 & $\mathrm{~N}$ \\
\hline Apocynaceae & Allamanda catartica L. & Alamanda & 2 & 0,09 & $\mathrm{~N}$ \\
\hline Bignoniaceae & Jacaranda mimosifolia D. Don & Jacarandá Mimoso & 2 & 0,09 & $\mathrm{~N}$ \\
\hline Melastomataceae & Tibouchina granulosa (Desr.) Cogn. & Quaresmeira & 2 & 0,09 & $\mathrm{~N}$ \\
\hline Myrtaceae & Psidium longipetiolatum D. Legrand & Araçá Vermelho & 2 & 0,09 & $\mathrm{~N}$ \\
\hline Anacardiaceae & Anacardium occidentale L. & Caju & 1 & 0,04 & $\mathrm{~N}$ \\
\hline Cactaceae & Cereus jamacaru D.C & Cacto Mandacaru & 1 & 0,04 & $\mathrm{~N}$ \\
\hline Cactaceae & Epiphyllum phyllantus (L.) Haw. & Entrada do Baile & 1 & 0,04 & $\mathrm{~N}$ \\
\hline Fabaceae & $\begin{array}{l}\text { Caesalpinia pluviosa DC. } \\
\text { var. peltophoroides (Benth.) G. P. Lewis }\end{array}$ & Sibipiruna & 1 & 0,04 & $\mathrm{~N}$ \\
\hline Fabaceae & Erythrina speciosa Andrews. & Eritrina & 1 & 0,04 & $\mathrm{~N}$ \\
\hline Fabaceae & Hymenaea courbaril L. & Jatobá & 1 & 0,04 & $\mathrm{~N}$ \\
\hline Myrtaceae & Eugenia brasiliensis Lam. & Grumixama & 1 & 0,04 & $\mathrm{~N}$ \\
\hline Myrtaceae & Plinia cauliflora (Mart) Kausel. & Jabuticaba & 1 & 0,04 & $\mathrm{~N}$ \\
\hline Myrtaceae & Psidium eugeniaefolia & Araçá Una & 1 & 0,04 & $\mathrm{~N}$ \\
\hline Marantaceae & $\begin{array}{l}\text { Ctenanthe oppenheimiana } \\
\text { (E.Morr) K.Schum }\end{array}$ & Maranta Variegada & 1 & 0,04 & $\mathrm{~N}$ \\
\hline Marantaceae & Ctenanthe setosa (Roscoe) Eichler & Maranta Cinza & 1 & 0,04 & $\mathrm{~N}$ \\
\hline
\end{tabular}

Figura 5. Densidade relativa das espécies nativas

Figure 5. Relative density of native species 
As espécies nativas são essenciais para o local de estudo, pois, estas espécies se adaptam muito bem aos fatores climáticos e físicos que ocorrem na região. Segundo Santos, Lima e Ferreira (2016), a arborização urbana não pode ser feita de maneira aleatória, pois a busca por espécies adaptadas as características físicas e ambientais da região devem iniciar no projeto, preferencialmente utilizando espécies nativas que já estão adaptadas ao meio e reduzindo os transtornos sociais e ambientais. Segundo Alencar et al. (2014), a inserção de indivíduos da mesma espécie em grande quantidade em um mesmo local é consequente da falta de planejamento, nas quais os órgãos públicos não visam a importância deste setor, introduzindo espécies sem nenhum conhecimento técnico.

Algumas espécies exóticas são invasoras como é o caso da Leucaena leucocephala (Lam.) de Wit. (Leucena). Esta espécie, bem como as demais invasoras, ameaçam a permanência das espécies nativas, degradando ambientes naturais. A ocorrência de espécies invasoras é a segunda causa de perda de diversidade no mundo e para evitar agravamentos a disseminação deve ser evitada (INSTITUTO DE BIOCIÊNCIAS USP, 2015). Foram encontradas e catalogadas sete espécies exóticas invasoras e a mais abundante foi a Ficus benjamina L. (Figueira) 102 indivíduos, seguido da Archontophoenix cunninghamiana H. Wendl. \& Drude (Palmeira Real) 84 indivíduos e a Livistona chinensis (Jack.) R. Br. Ex. Mart. (Palmeira Leque) 36 indivíduos.

Nem toda espécie exótica é invasora, para tornar-se é preciso ter sucesso competitivo do que espécies nativas, em relação a ocupação de ambientes e precisa disseminar no novo ambiente para aumentar suas populações e causar danos ao ambiente, podendo então ameaçar ecossistemas, habitats e até mesmo espécies.

O índice de diversidade de Shannon calculado para as praças de Caraguatatuba foi $H^{\prime}=$ 4,16, ficando abaixo do observado no município de Gurupi - TO com 4,77 (SILVA et al., 2019). Entretanto foi superior ao observado nos municípios de Ribeirão Preto - SP com 3,14 (ROMANI et al., 2012). Este índice, portanto, demonstra a uniformidade da biodiversidade, levando em consideração as espécies dominantes e o número de espécies inventariadas.

Para 161 espécies catalogadas, não foi encontrado status de conservação na Portaria MMA 443, de 17 de dezembro de 2014, que listam espécies em risco de extinção, sugerindo que as espécies observadas são comumente encontradas.

Foi observada a predominância de espécies sem status de ameaça, entretanto foi encontrado apenas um indivíduo da espécie Jacaranda mimosifolia, relatada com o status de vulnerável (VU) no Livro Vermelho da IUCN, mas não possui status catalogado na Portaria de MMA.

Todavia, no Livro Vermelho já houve uma classificação para algumas espécies encontradas e que não foram observadas na MMA, como a Dypsis lutescens $\mathrm{H}$. Wendl. Beetje 
\& J. Dransf (Areca-Bambu), que no MMA foi identificada na categoria Sem Status, mas no Livro Vermelho foi identificada na categoria Quase Ameaçada (NT). A Hyophorbe lagenicaulis (H.E.Moore) (Palmeira Garrafa) e a Phoenix roebelenii O'Brien (Palmeira Fênix) foram classificadas na categoria Sem Status (SS), mas no MMA como Perigo Crítico (PR) no livro vermelho. Ao menos três espécies foram categorizadas com Dados Insuficientes (DD);

O porte arbóreo também foi identificado e o porte de árvores (AR), foram os mais abundantes, com 37\%, seguido do porte Arbustos (AB) com 34\%, Herbáceas (HB) com 17\%, Palmeiras (PA) com $8 \%$, Pinheiros (PI) com 3\% e Cicadáceas (CY) com somente 1\% das identificações (Figura 6).

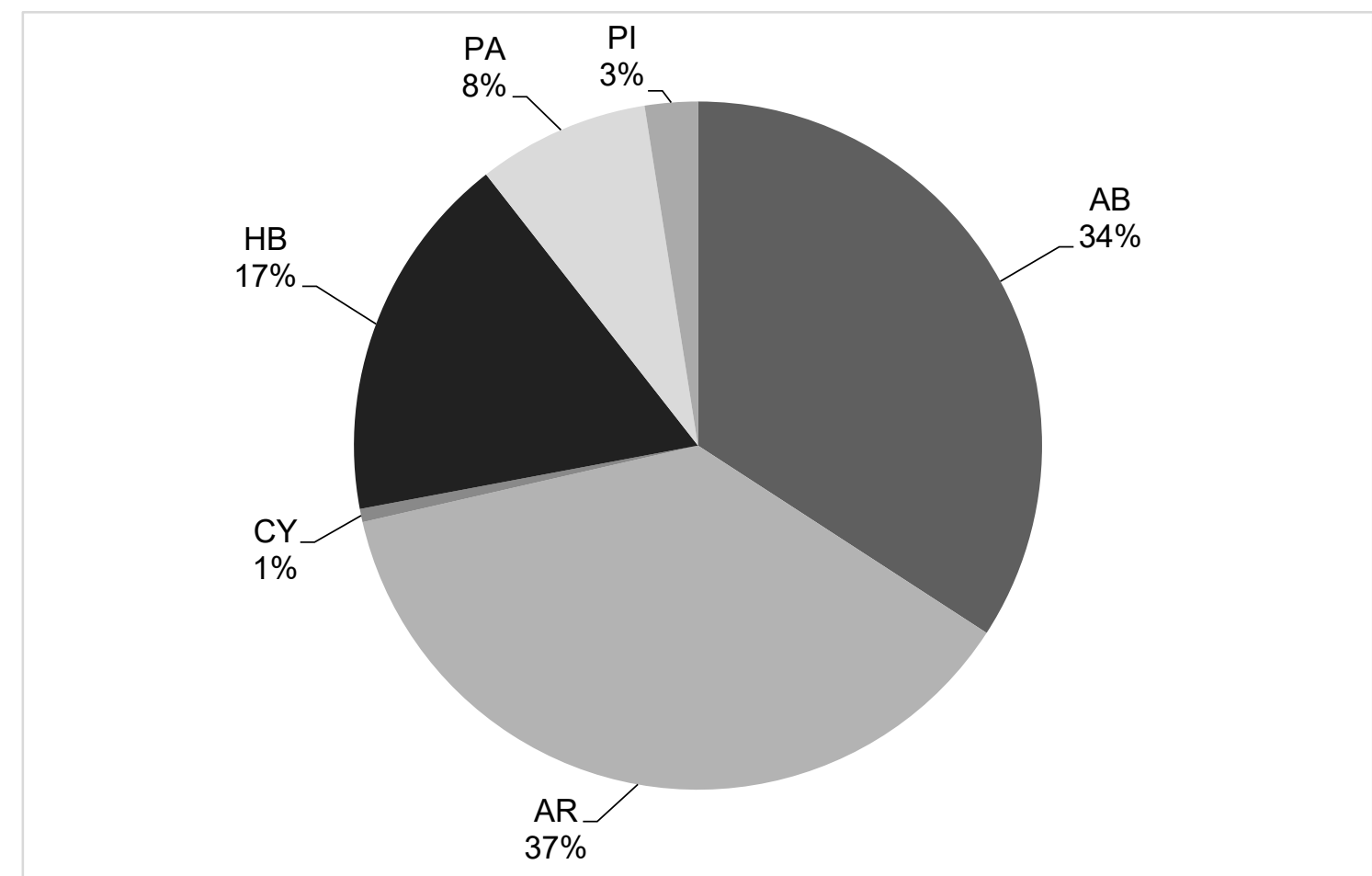

Fonte: Autores, 2020.

Figura 6. Portes arbóreos mais identificados no estudo Figure 6. Tree sizes most identified in the study

O porte arbóreo (AR) foi o mais abundante (37\%), entretanto não apresentou grande variação em relação ao porte arbusto $(A B)(34 \%)$ que vem sendo muito utilizado em todas as praças. Isso ocorre principalmente por sua facilidade na implantação e no manejo, além de evitar danos aos componentes urbanos como calçadas, ruas e fios elétricos. De acordo com Pereira, et al. (2020), o fenômeno de "arbustificação" vem tornando-se tendência nas cidades brasileiras, devido a calçadas pequenas, falta de recuo com a rua, que impossibilita o desenvolvimento de espécies arbóreas de grande porte. 
Os componentes arbóreos a nível específico e quanto à sua disposição e densidade estrutural foram categorizados nas praças e o percentual encontra-se representado nas Figuras 7 e 8.

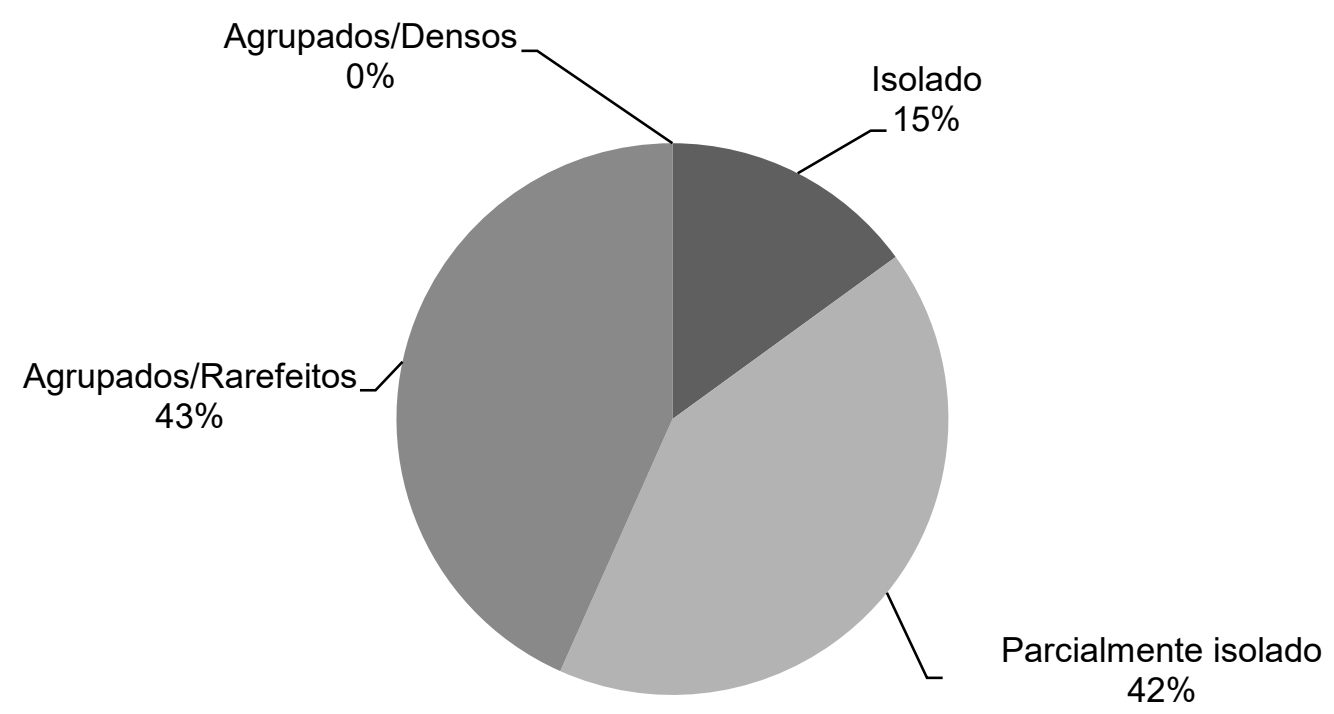

Fonte: Autores, 2020.

Figura 7. Densidade de árvores das áreas verdes catalogadas

Figure 7 . Tree density of the cataloged green areas

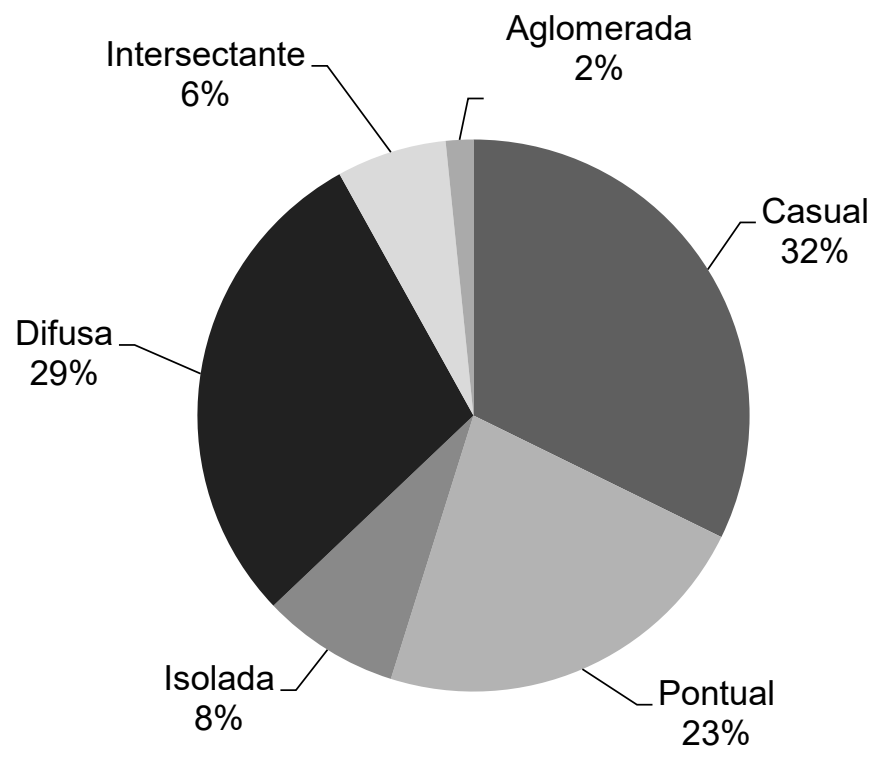

Fonte: Autores, 2020.

Figura 8. Disposição dos indivíduos nas áreas verdes catalogadas

Figure 8. Disposition of individuals in the cataloged green areas

A densidade mais observada foi a de Agrupados/Rarefeitos, justamente por estarem empregados em praças públicas, trazendo uma ideia de sombreamento no local, para uso da 
população do município. Algumas praças em que havia poucas espécies ou eram muito pequenas e limitadas, a ocorrência de indivíduos isolados ou parcialmente isolados eram maiores. Segundo Labaki et al. (2012), árvores isoladas ou em grupos impedem grande parte da radiação solar, propiciando um bom resfriamento do solo ou construção por meio do sombreamento e da evapotranspiração e auxilia em condições extremas de frio e calor intenso.

Não foi encontrada em nenhuma das praças a densidade de Agrupados/Densos, pois as áreas verdes na zona urbana são planejadas para que os indivíduos arbóreos não fiquem muito próximos uns dos outros, havendo, portanto, uma distância de plantio selecionada, diminuindo os riscos de uma espécie sobrepor à outra. Segundo Labaki et al. (2012), os agrupamentos arbóreos influenciam mais do que somente uma árvore isolada e a maior disposição delas aumentam a capacidade de redução da temperatura do ar e a diminuição a radiação solar, intensificando o conforto térmico para a população ao seu redor. As áreas verdes são muito importantes para a zona urbana, pois são elas que conseguem trazer a sensação de conforto térmico para quem está no local, mas também para a população ao redor. Soares et al. (2018) afirmam que estes bairros com maior predominância de áreas verdes são justamente os que possuem maiores valores de mercado. Além das identificações arbóreas, foi feito a identificação do mobiliário urbano disponibilizado em cada praça, representado na Figura 9.

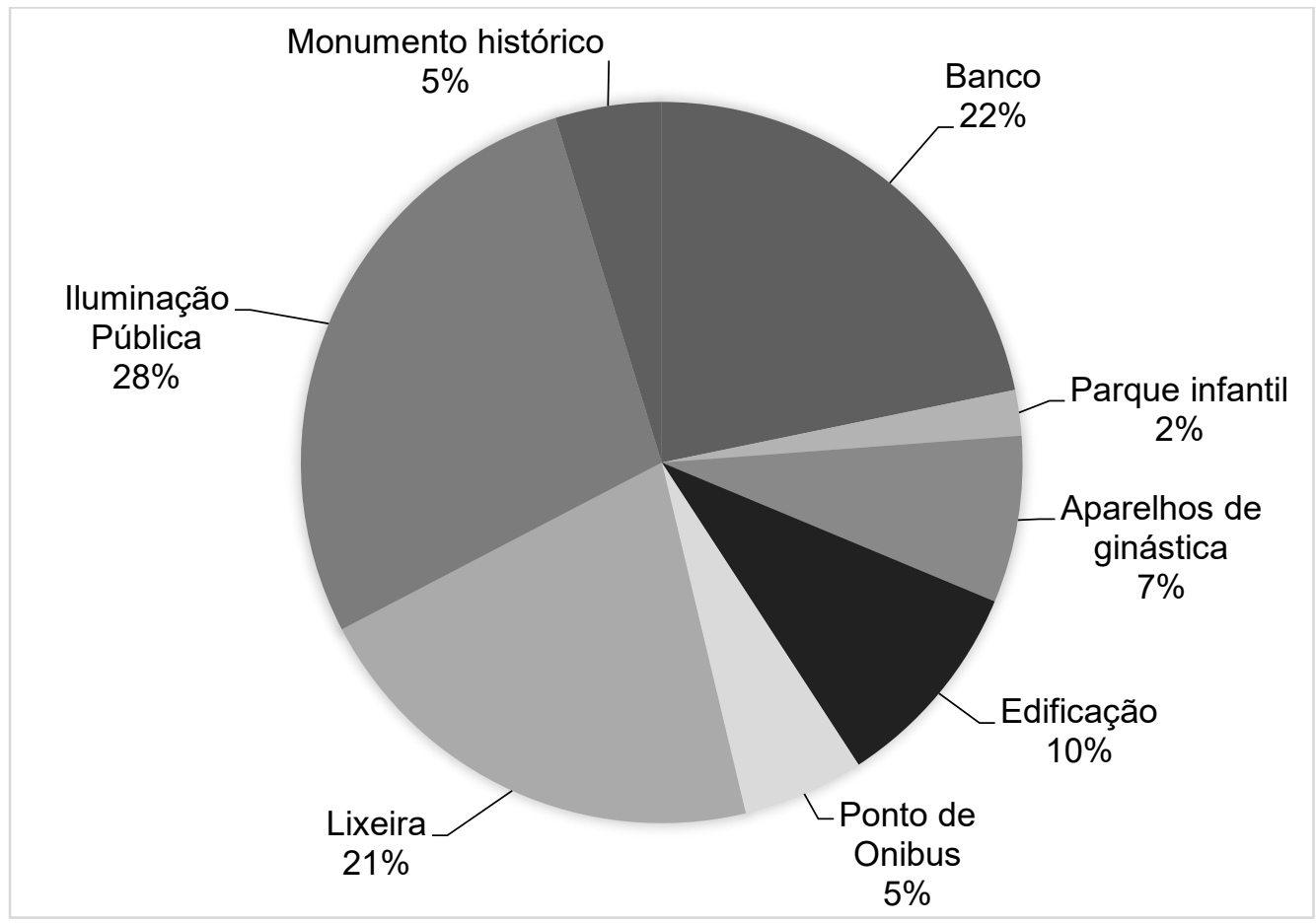

Fonte: Autores, 2020.

Figura 9. Porcentagem de mobiliário urbano nas praças de Caraguatatuba-SP

Figure 9. Percentage of urban furniture in the squares of Caraguatatuba-SP 
Foram encontradas praças que não possuíam nenhum tipo de mobiliário urbano, pois não possuíam bancos, lixeiras e/ou iluminação que transformam a área verde, em um local de lazer para a população.

O mobiliário urbano interfere nas áreas verdes, pois afeta diretamente, principalmente na qualidade visual, mas que não pode interferir negativamente. John e Reis (2010), afirmam que os projetistas do mobiliário urbano devem considerar a percepção dos usuários e que esse espaço deve ser utilizado de maneira contextualizada e que as implantações sejam satisfatórias aos usuários e não somente a estética, mas também a sua adequação de uso dos espaços públicos.

\section{CONCLUSÕES}

Uma cidade com clima tropical como Caraguatatuba necessita de praças recobertas por vegetação, e isso foi documentado com a presença de 2.233 indivíduos arbóreos, nas 59 praças públicas de Caraguatatuba. Notou-se a presença de 161 espécies, gerando um alto índice de diversidade, porém $70 \%$ delas são exóticas. Além disso, foram inventariadas sete espécies classificadas como invasoras, que apresentam alta capacidade de disseminação e possível ameaça às espécies nativas, já que algumas praças apresentam sua localização próxima à zona de amortecimento do Parque Estadual da Serra do Mar. Observou-se a presença de quatro espécies com diferentes graus de ameaçadas de extinção na Lista Vermelha da União Internacional para Conservação da Natureza, sugerindo o cuidado com a manutenção destes indivíduos, principalmente com as frequentes podas de condução.

Quanto ao porte, no município valoriza-se o plantio de indivíduos arbóreos, que com sua arquitetura, proporcionam melhoria eficiente no conforto térmico. A densidade dos indivíduos arbóreos foi casual/rarefeito propiciando assim bom resfriamento do solo pelo sombreamento. As praças do município se encontram algumas vezes divididas por ruas e rodovias, o que dificulta o lazer de moradores nestes locais pela incidência de carros circulando. Apesar do alto índice de diversidade faz-se necessário o enriquecimento nos plantios das áreas urbanas, priorizandose espécies nativas e consequentemente aumentando assim os serviços ecossistêmicos.

Notou-se que de forma geral há carência de mobiliário urbano em parte das praças. $\mathrm{A}$ iluminação pública está presente em $28 \%$ das praças, bancos em $22 \%$, lixeiras em $21 \%$ e edificações em $10 \%$ das praças. 


\section{REFERÊNCIAS}

ALENCAR, L. S. A.; SOUTO, P. C.; MOREIRA, F. T. A.; SOUTO, J. S.; BORGES, C. H. A. Inventário quali-quantitativo da arborização urbana em São João do Rio do Peixe - PB. Agropecuária Científica no Semiárido, Campina Grande, v. 10, n. 2, p. 117-124, 2014.

BENATTI, D. P.; TONELLO, K. C.; ADRIANO, J.; FRANCISCO C.; JOSÉ M. S. O.; IVANKA R. R.; ELCE N.; FERRAZ, D. L. Inventário arbóreo-urbano do município de Salto de Pirapora, SP. Revista Árvore, Viçosa, v. 36, n. 5, p. 887-894, 2012.

CLIMATE DATA ORG. Disponível em: <https://pt.climate-data.org/americado-sul/brasil/saopaulo/caraguatatuba14939/\#climate-graph>. Acesso em: 16 fev. 2021.

DAMO, A.; HEFLER, S. M.; JACOBI, U. S. Diagnóstico da arborização em vias públicas dos bairros cidade nova e centro na cidade de Rio Grande - RS. Revista da Sociedade Brasileira de Arborização Urbana, Piracicaba, v. 10, n. 1, p. 43-60, 2015.

FARIAS, A. R; MINGOTI, R.; VALLE, L. B.; SPADOTTO, C. A.; LOVISI E. F. Identificação, mapeamento e quantificação das áreas urbanas do Brasil. 2017. Disponível em: <https://ainfo.cnptia.embrapa.br/digital/bitstream/item/176016/1/20170522-COT-4.pdf>. Acesso em: 26 dez. 2019.

FIGUEIREDO, P. P. R. A.; ENSSLIN, A. R.; MATOS, L. S. Avaliação de desempenho para o desenvolvimento do urbanismo sustentável: Revisão de literatura e diretrizes para futuras investigações. Mix Sustentável, Florianópolis.v.3. n.2. p.114- 124. 2017.

INSTITUTO BRASILEIRO DE GEOGRAFIA E ESTATÍSTICA (IBGE). Área da unidade territorial 2020. Disponível em: https://cidades.ibge.gov.br/brasil/sp/caraguatatuba/ panorama. Acesso em 16 fev. 2021.

INSTITUTO DE BIOCIÊNCIAS (IBUSP). Vegetação associada a depressões. São Paulo: USP, 2015. Disponível em <http://www.ib.usp.br/ecosteiros/textos_educ/restinga/ caract/depressoes.htm>. Acesso em: 14 out. 2015.

JOHN, N. M.; REIS, A. T. L. Percepção, estética e uso do mobiliário urbano. Gestão \& Tecnologia de Projetos, Rio Grande do Sul. v. 5, n. 2, p.180-206. 2010.

KRAMER, J. A.; KRUPER, R. A. Caracterização florística e ecológica da arborização de praças públicas do município de Guarapuava, PR. Revista Árvore, Viçosa, v. 36, n. 4, p. 647-658, 2012.

LABAKI, L. C.; CASTRO, M. S. G.; BUENO-BARTHOLOMEI, LOTUFO C.; DACANAL, C. Conforto térmico em espaços públicos de passagem: estudos em ruas de pedestres no estado de São Paulo. Ambient. constr., Porto Alegre. v. 12, n. 1, p. 167-183. 2012.

LORENZI, H. Árvores Brasileiras: Manual de Identificação e Cultivo de Plantas Arbóreas Nativas do Brasil. Vol 1 - 1. ed Nova Odessa, SP, 1992. 348p.

LORENZI, H. Árvores Brasileiras: Manual de Identificação e Cultivo de Plantas Arbóreas Nativas do Brasil. Vol 2 - 2. ed. Nova Odessa, SP, 1998. 384p.

LORENZI, H. Árvores Brasileiras: Manual de Identificação e Cultivo de Plantas Arbóreas Nativas do Brasil. Vol 3 - 1. ed. Nova Odessa, SP. 2017. 384p. 
MARTINELLI, G.; MORAES, M. A. Livro vermelho da Flora do Brasil. 1. ed. - Rio de Janeiro, Instituto de Pesquisas Jardim Botânico do Rio de Janeiro, 2013. 1100p.

MINISTÉRIO DO MEIO AMBIENTE (MMA). Portaria MMA n 443 de 17 de dezembro de 2014. Disponível em: <https://www.mma.gov.br/cidades-sustentaveis/areas-verdes-urbanas/item/ 8051.html>. Acesso em: 16 fev. 2021.

PEIXOTO, M. C., LABAKI, L. C., SANTOS, R. F. Conforto térmico em cidades: o efeito da arborização no controle da radiação solar. Anais... Rio de Janeiro. p. 629-634. 1995.

PEREIRA, G. A.; BARBOSA, A. C. M. C.; OLIVEIRA, A. F.; SILVA, E. M. G. C.; POMPEU, P. V.; CASTRO, M. B. Diagnóstico florístico da arborização urbana no Brasil e no município de Lavras - MG. Revista da Sociedade Brasileira de Arborização Urbana, Curitiba, v.15, n.1, p. 13-25, 2020.

PREFEITURA DO MUNICÍPIO DE SÃO PAULO (PMSP). Guia de boas práticas para os espaços públicos da cidade de São Paulo. São Paulo: Secretaria Municipal de Desenvolvimento Urbano - SMDU, 2016. Disponível em: <https://gestaourbana.prefeitura. sp.gov.br/wp-content/uploads/2016/12/20161230_GBPEP.pdf>. Acesso em: 08 maio 2019.

ROMANI, G. N.; GIMENES, R.; SILVA, M. T.; PIVETTA, K. F. L.; BATISTA, G. S. Análise qualiquantitativa da arborização na praça XV de Novembro em Ribeirão Preto - SP, Brasil. Revista Árvore, Viçosa. v.36, n.3, p.479-487. 2012.

SANTOS, A. F.; JOSÉ, A. C.; SOUSA, P. A. Fitossociologia e diversidade de espécies arbóreas das praças centrais do município de Gurupi - TO. Revista da Sociedade Brasileira de Arborização Urbana, Piracicaba. v. 8, n. 4, p. 36-46. 2019.

SANTOS, F. S.; LIMA, D. P.; FERREIRA, R. M. Levantamento de Espécies Arbóreas em Via Urbana do Município de Foz do Iguaçu-Paraná. Biota Amazônia, Foz do Iguaçú. v. 6, n. 3, p.5254. 2016.

SILVA, A. D. P.; BATISTA, A. C.; GIONGO, M. V.; BIONDI, D.; SANTOS, A. F.; OLIVEIRA, L. M.; CACHOEIRA, J. N. Arborização das Praças de Gurupi - TO - BRASIL: composição e diversidade de espécies. Revista da Sociedade Brasileira de Arborização Urbana. Curitiba.14, n.4, p. 0112. 2019.

SOARES, T.R.; DE SOUZA, P.G.; KOEHLER, A.B.; RIBASKI, N. G. Estudo da Percepção da População de Curitiba - PR em Relação ao Valor das Áreas Verdes. Brazilian Journal of Animal and Environmental Research, Curitiba, v. 1, n. 1, p. $134-167,2018$.

TEIXEIRA, I. F.; FIGUEIREDO, F. M.; TABORDA, I. G. R.; SOAREAS, L. M. Análise fitossociológica da Praça Camilo Mércio no centro histórico de São Gabriel, RS. Revista da Sociedade Brasileira de Arborização Urbana, Piracicaba. v. 11, n. 1, p. 01-13. 2016. 